Neuroepidemiology 2005;24:168-169

DOI: $10.1159 / 000083613$

\section{Does Donepezil Improve Well-Being for Dementia due to Alzheimer's Disease?}

\author{
Jacqueline Birks \\ on behalf of the Cochrane Neurological Network
}

\section{Question}

Does donepezil improve well-being for dementia due to Alzheimer's disease?

\section{Data Source}

Cochrane systematic review of randomized controlled trials [1] Trials were identified on October 9, 2002 through a search of the Cochrane Dementia and Cognitive Improvement Group's Specialized Register which contains records from all main medical databases (Medline, Embase, CINAHL, PsycINFO, SIGLE, LILACS), from ongoing trials databases such as Clinicaltrials.gov and Current Controlled Trials and many other sources. The search terms used were: donepezil, Aricept, and E2020.

\section{Patients}

Most patients were diagnosed as having probable Alzheimer's disease using criteria such as ICD-10, DSM-III-R and NINCDSADRDA (National Institute of Neurological and Communicative Disorders and Stroke - Alzheimer's Disease and Related Disorders Association). The severity of dementia was assessed according to the Mini-Mental State Examination (MMSE $=10-26)$ or the Clinical Dementia Rating $(\mathrm{CDR}=1$ (mild) or $=2$ (moderate)). Two studies included patients with severe dementia (MMSE $=5-17)$. Patients with other serious illnesses were mostly excluded. Concomitant medication was restricted.

\section{Treatment}

Donepezil was not prescribed at less than $5 \mathrm{mg} /$ day. Although smaller doses were tested in some trials, only two doses were used in the phase-III trials, 5 or $10 \mathrm{mg} /$ day. Patients randomized to $5 \mathrm{mg} /$ day began with the full dose, those randomized to $10 \mathrm{mg} /$ day began with $5 \mathrm{mg} /$ day for 1 or 4 weeks before increasing to $10 \mathrm{mg} /$ day. Treatment was once daily.

\section{Outcome Measures}

The Clinician's Interview-Based Impression of Change scale (CIBIC-plus), cognition (MMSE and the Alzheimer's Disease Assessment Scale, cognitive subscale-ADAS-cog), activities of daily living (ADL), quality of life and behavioral disturbance as assessed by cognitive tests or rating scales. The number of patients experiencing adverse events. The number of patients dropping out before the scheduled end of treatment.

\section{Quality of Studies}

All trials were randomized, double-blind, parallel group and placebo-controlled. The percentage of non-completers was less than $20 \%$ at 6 months. The numbers were similar in the placebo and lowdose group, but higher in the $10-\mathrm{mg} /$ day group. The main cause of non-completion was an adverse event. The primary end-point for one study, which contributed little data to the results of the review, was time to clinically evident decline in function, at which point patients left the study and received donepezil treatment.

\section{Main Results}

4,367 patients in 16 trials were included, and 3,657 (14 trials) contributed to the results. 1,283 patients were treated for 1 year, 2,166 for 6 months and 930 for 3 months. At 6 months, donepezil $(10 \mathrm{mg} /$ day) was associated with an improvement in the dichotomized CIBIC-plus, in cognition as assessed by the ADAS-cog and MMSE, and in the ADL compared with placebo. The adverse events
Table 1. Benefit and risk of donepezil $(10 \mathrm{mg} /$ day $)$ at 6 months in Alzheimer's disease

\begin{tabular}{lllll}
\hline Events/treatment & Events/placebo & OR & $95 \% \mathrm{CI}$ & $\mathrm{p}$ \\
\hline $\begin{array}{l}\text { CIBIC-plus improvement } \\
97 / 390\end{array}$ & $\begin{array}{l}6 \text { months } \\
53 / 409\end{array}$ & 2.18 & $1.53-3.11$ & $<0.0001$ \\
$25 \%$ & $13 \%$ & & & \\
\hline $\begin{array}{l}\text { Adverse events } \\
453 / 554\end{array}$ & 6 months & & & \\
$82 \%$ & $427 / 559$ & 1.57 & $1.13-2.20$ & 0.008 \\
\hline $\begin{array}{l}\text { Drop-outs } \\
111 / 482\end{array}$ & 6 months & & & \\
$23 \%$ & $88 / 394$ & 1.09 & $0.79-1.50$ & 0.61 \\
\hline
\end{tabular}


were seen most frequently in the $10-\mathrm{mg} /$ day donepezil group, compared with the placebo group and were mainly gastrointestinal (anorexia, diarrhea, nausea and vomiting).

\section{Conclusion}

The results from 7 trials demonstrate beneficial effects of donepezil compared with placebo at 6 months on cognitive function, ADL, behavioral disturbance and global clinical state. The size of the effects is dose-related being greater for the higher dose, and appears unrelated to the severity of dementia. Adverse effects were consistent with the cholinergic action of the drug and were most likely to lead to withdrawal in the first 12 weeks of treatment.

\section{Comment}

Donepezil is associated with some benefits in cognition, behavior and ADL in patients with mild to moderate Alzheimer's disease after 6 months of treatment. Evidence for the effectiveness of treatment for 1 year is controversial [2].

\section{References}

1 Birks J, Harvey R: Donepezil for dementia due to Alzheimer's disease (Cochrane Review); in The Cochrane Library, Issue 4. Chichester, Wiley, 2003.

2 AD2000 Collaborative Group: Long-term donepezil treatment in 565 patients with Alzheimer's disease (AD2000): Randomised double-blind trial. Lancet 2004;363:2105-2115.

Cochrane Neurological Network, Dipartimento di Scienze Neurologiche Via F. Sforza 35, IT-20122 Milan (Italy)

E-Mail cochrane.neuronet@unimi.it

Website: http://www.cochraneneuronet.org 